University of South Florida

DIGITAL COMMONS

Digital Commons @ University of

@ UNIVERSITY OF SOUTH FLORIDA

South Florida

7-1988

\title{
Vertical Structure of Low-Frequency Variability in the Eastern Equatorial Pacific Ocean
}

\author{
T. Y. Tang \\ University of South Florida \\ Robert $\mathrm{H}$. Weisberg \\ University of South Florida, weisberg@marine.usf.edu \\ D. Halpern \\ California Institute of Technology
}

Follow this and additional works at: https://digitalcommons.usf.edu/msc_facpub

Part of the Marine Biology Commons

\section{Scholar Commons Citation}

Tang, T. Y.; Weisberg, Robert H.; and Halpern, D., "Vertical Structure of Low-Frequency Variability in the Eastern Equatorial Pacific Ocean" (1988). Marine Science Faculty Publications. 140.

https://digitalcommons.usf.edu/msc_facpub/140

This Article is brought to you for free and open access by the College of Marine Science at Digital Commons @ University of South Florida. It has been accepted for inclusion in Marine Science Faculty Publications by an authorized administrator of Digital Commons @ University of South Florida. For more information, please contact digitalcommons@usf.edu. 


\title{
Vertical Structure of Low Frequency Variability in the Eastern Equatorial Pacific Ocean
}

\author{
T. Y. TANG AND R. H. WEISBERG \\ Department of Marine Science, University of South Florida, St. Petersburg, Florida \\ D. HALPERN \\ Jet Propulsion Laboratory, California Institute of Technology, Pasadena, California
}

(Manuscript received 13 July 1987, in final form 5 January 1988)

\begin{abstract}
The vertical structure of low frequency velocity and temperature variability in the eastern equatorial Pacific Ocean is examined using surface and subsurface moored current meter data from $0^{\circ}, 110^{\circ} \mathrm{W}$ between 20 and $3027 \mathrm{~m}$ depths over the period 30 March 1980 to 2 February 1981. Three methods of analysis are employed: vertical coherence, empirical orthogonal functions, and linear least-squares dynamical mode decompositions. Direct evidence is given for the existence of first baroclinic mode Kelvin waves in the east component of velocity and vertical displacement (estimated from temperature) in that the vertical displacement is coherent and in phase over the water column and the upper-ocean east component of velocity varies out of phase with the vertical displacement over the water column. Near-surface modifications due to advection, nonadiabatic processes, and local forcing are also noted.
\end{abstract}

\section{Introduction}

Understanding the dynamics of the equatorial oceans has been a prime concern of tropical air-sea interaction and global climate modelers since the processes that determine sea surface temperature near the equator effectively couple the ocean with the atmosphere. Low-frequency equatorially trapped waves have been used in both the construction of analytical models and in the interpretation of numerical models. For example, the simplest equatorial ocean models, successful in hindcasting surface dynamic height variations associated with El Niño-Southern Oscillation events, have used a reduced-gravity formulation assuming a single baroclinic vertical mode (e.g., Busalacchi et al. 1983). The fully nonlinear high vertical resolution ocean models (e.g., Philander and Seigel 1985), while demonstrating the complexity of the system, have not undermined the finding that for vertically integrated quantities such as surface dynamic height or heat content the phasing of the observed patterns are consistent with a simple baroclinic modal structure. Although low frequency, vertical baroclinic mode, equatorially trapped waves have been used in both models and data interpretations by many investigators, the existence of such modes in the equatorial oceans has been without direct observational verification. The purpose of the

Corresponding author address: Dr. Robert H. Weisberg, Dept. of Marine Science, University of South Florida, 140 Seventh Ave. South, St. Petersburg, FL 33701. present paper is to provide such verification by analyzing velocity and temperature time series obtained over the water column in the eastern equatorial Pacific Ocean.

Indirect evidence of low vertical-mode equatorial Kelvin waves based upon eastward phase propagation and meridional structure is abundant. Luther (1980) identified eastward propagation speeds consistent with a first baroclinic mode in an extensive analysis of Pacific island sea level records over the range of 35-80 day periodicities. Ripa and Hayes (1981) fit empirical orthogonal functions to the meridional distribution of sea level fluctuations at neighboring Galapagos Islands and found the scaling to be consistent with a first baroclinic-mode Kelvin wave. Knox and Halpern (1982) compared vertically integrated eastward transport from surface moored current meters in the upper $250 \mathrm{~m}$ at $152^{\circ} \mathrm{W}$ and $110^{\circ} \mathrm{W}$ and also found consistency between the phase lag and the speed of a Kelvin wave. Eriksen et al. (1983) and Lukas et al. (1984) analyzed sea level records from the western Pacific and the Galapagos and claim to trace such Kelvin waves across a major portion of the ocean basin. Katz (1987), using inverted echo sounder records bandpass filtered between 10-40 day periodicities, provides a similar argument for the Atlantic Ocean.

Direct measurements intended to observe vertical structure were made by Eriksen (1982). Temperature sensors were moored at the depth of maximum vertical displacement for a first baroclinic mode near an island sea level station in the western Pacific. Evidence in 
support of first baroclinic mode, equatorially trapped inertia-gravity waves over the range of several day periodicities was found in that, where coherent, sea level and deep temperature fluctuations were either in phase or $\pi$ radians out of phase. However, at lower frequencies the observed phase difference was $\pi / 2$ radians, which is not consistent with a vertical mode. Behringer (1984) analyzed isopycnal displacements from $4.5^{\circ} \mathrm{N}$ to $4.5^{\circ} \mathrm{S}$ along $85^{\circ} \mathrm{W}$ over the upper $1000 \mathrm{~m}$ estimated from CTD data obtained in November and December 1982-a period of dramatic change due to the evolution of an El Niño that year. The latitudinal structure was indicative of a first baroclinic-mode Kelvin wave.

From 30 March 1980 to 2 February 1981 a subsurface mooring was deployed approximately $80 \mathrm{~km}$ to the west of a surface mooring along the equator near $110^{\circ} \mathrm{W}$. They yielded simultaneous measurements of horizontal velocity and temperature at 10 depths spanning the water column from 20 to $3027 \mathrm{~m}$. Hayes and Halpern (1984) present the surface mooring data between depths of 20 and $150 \mathrm{~m}$ ( $250 \mathrm{~m}$ for temperature) and compare these with sea level data at the Galapagos over the period March 1980 to July 1981. The north component of velocity was shown to differ in character from the east component when low-pass filtered to exclude fluctuations at time scales shorter than 30 days. The low-pass filtered and vertically averaged east component over the upper $150 \mathrm{~m}$ was found to be correlated with the similarly low-pass filtered sea level record at the Galapagos with a phase lag approximating that attributable to a first baroclinic-mode Kelvin wave. Not only was the phase in agreement but, from the surface boundary condition on vertical displacement, the amplitudes of the vertically averaged east component (argued to be a proxy for the surface speed of a first baroclinic mode) and sea level were in the correct proportion. These findings led to the inference once again that a first baroclinic mode was observed. Given these inferences we proceed to analyze the vertical structure of low frequency horizontal velocity component and temperature variability over the entire water column.

The paper continues with a description of the data in section 2. The coherence structure between individual variables and among the different variables over the water column is given in section 3 . Section 4 provides a time-domain empirical orthogonal function analysis followed by a dynamical mode decomposition in section 5. The results are summarized and discussed in section 6 where it is concluded that low-frequency first baroclinic-mode equatorial Kelvin waves were indeed present.

\section{Data description}

The data at 20,50 and $100 \mathrm{~m}$ were recorded by vector-averaging current meters (VACM) suspended beneath a taut moored surface-following buoy while the data at $277 \mathrm{~m}$ and below were collected using cur- rent meters suspended from a subsurface buoy with a VACM at $277 \mathrm{~m}$ and Aanderaa RCM4 current meters at $727,927,1027,2027,2127$ and $3027 \mathrm{~m}$. Both moorings were within $2 \mathrm{~km}$ of the equator with the surface mooring $80 \mathrm{~km}$ to the east of the subsurface mooring. Water depth in this region is between 3600 and 4000 m. Intercomparison tests by Halpern and Pillsbury (1976) indicate that differences between a VACM and a RCM4 are not significant enough to bias the results presented here. Further tests by Halpern (1987a) establish the suitability of VACM from surface moorings for equatorial applications.

In order to focus upon the low frequency variability, all the data were low-pass filtered to remove fluctuations at time scales shorter than 36 days using a truncated Fourier transform after subtracting the mean and tapering the ends of the time series to reduce the Gibbs effect. This particular cutoff was chosen to exclude from the analyses the energetic oscillations occurring at time scales around 21 days that arise by surface current instability (e.g., Philander et al. 1985). Figures 1 and 2 show the resulting east and north velocity component time series respectively, and Fig. 3 gives the average

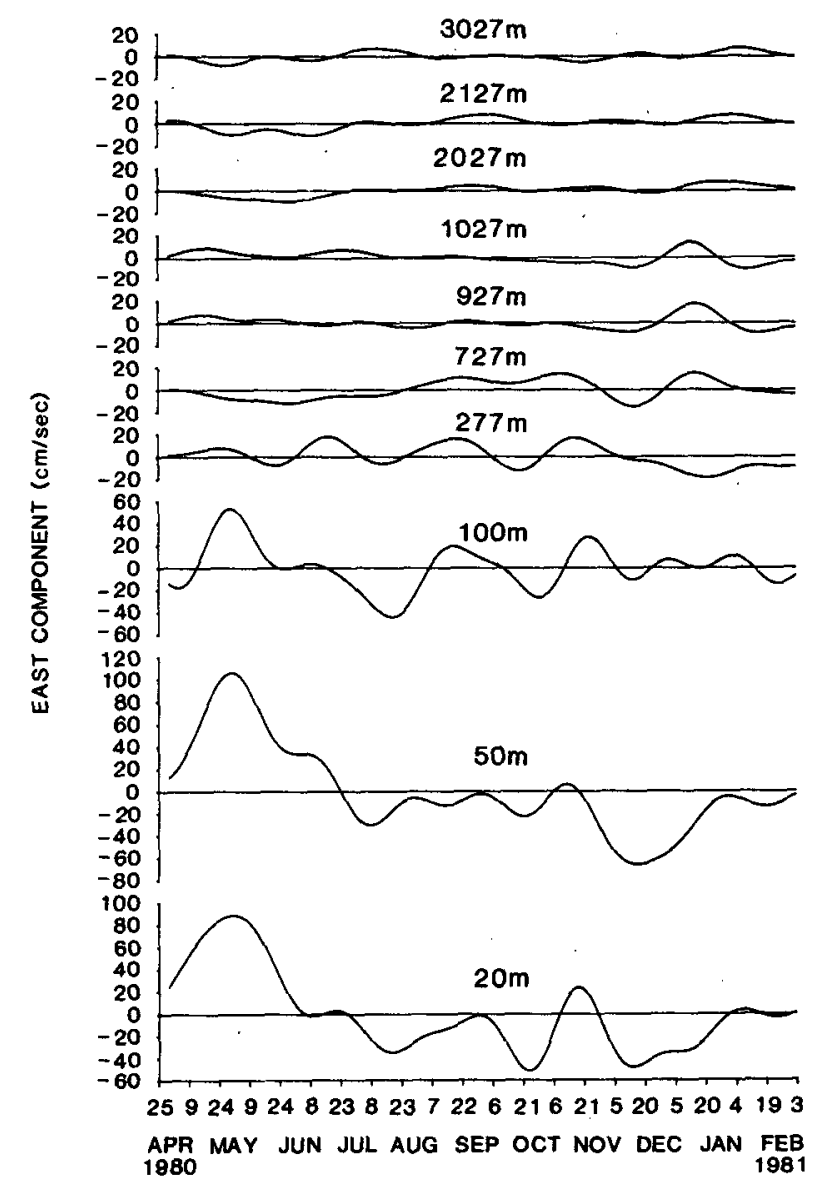

FIG. 1. Low-pass filtered east velocity component fluctuations at the ten depths of record. 


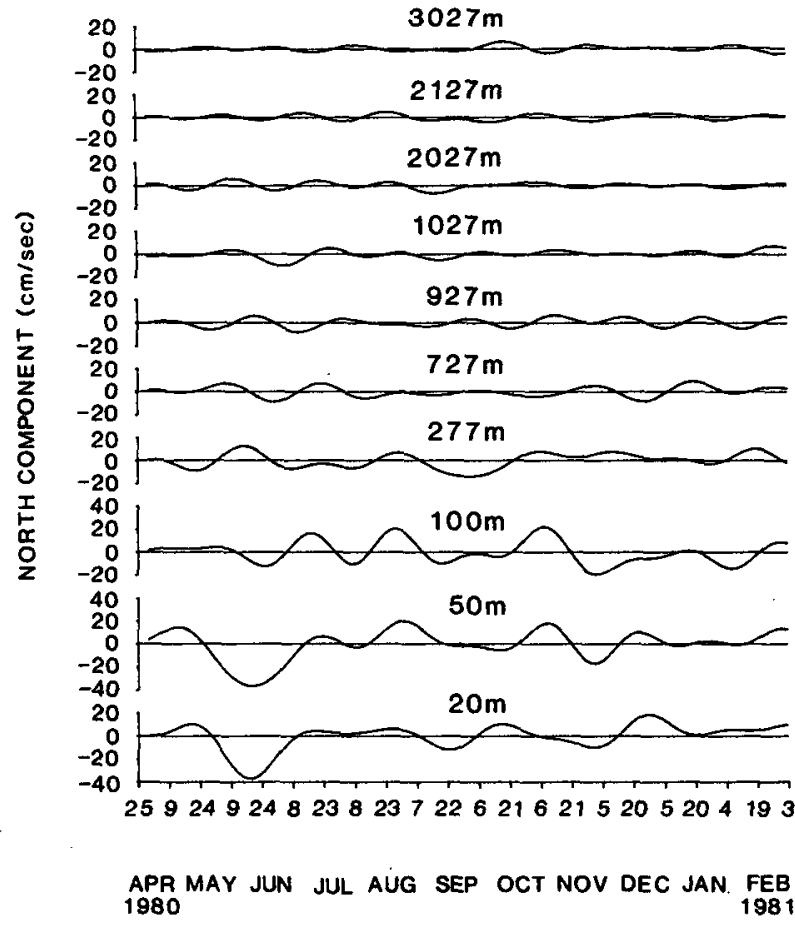

FiG. 2. As in Fig. 1 but for the north component.

horizontal velocity hodographs and ellipse stabilities calculated by rotary spectrum analysis. The orientation of the hodographs is approximately zonal at all depths consistent with the anisotropy expected for equatorial low frequency motions (e.g., Cane and Sarachik 1976). Ellipse stability is highest near the surface, indicative of some coupling between the orthogonal velocity components there. The ellipses flatten with depth and decrease in amplitude across the thermocline.

The east component record commences with an approximate two-month surge in eastward flow that appears to be in phase over the upper $277 \mathrm{~m}$. This is typical of April and it is part of the annual cycle as shown in five years of upper-ocean current meter data by Halpern (1987b). While the flow at $2027 \mathrm{~m}$ and below is out of phase with the near-surface flow initially, no obvious patterns exist over depth for all times. The north component records show less resemblance with depth than the east component. The most noticeable feature is a near-surface southward flow during the latter portion of the initial eastward surge. Temperature shows a broad period of near-surface warming accompanying the eastward surge and subsequent southward flow. Highest temperatures at 20 and $50 \mathrm{~m}$ coincide with maximum southward flow. However, this is not the case at $100 \mathrm{~m}$, and below $100 \mathrm{~m}$ the temperature fluctuations are very small.

In order to examine the vertical structure of the thermal field, temperature was converted to vertical displacement using the heat equation. Neglecting hor- izontal advection, diffusion, and heat sources, the vertical displacement $h(z, t)$ was estimated by

$$
h(z, t)=[T(z, t)-\bar{T}(z)] / \bar{T}_{z}(z)
$$

where $T(z, t)$ is the instantaneous temperature, $\bar{T}(z)$ is the mean temperature at depth $z$, and $\bar{T}_{z}(z)$ is the mean vertical temperature gradient obtained from the average CTD casts made in the study area during July 1979 (Hayes, S. P., personal communication, 1984) further smoothed to remove high vertical wavenumber variability. This adiabatic and no horizontal advection assumption may be applicable at depth however it is probably of little validity near the surface as will be commented upon later. The vertical displacement time series thus calculated are shown in Fig. 4. Visually the correlations appear to be much stronger for $h(z, t)$ than for the velocity components. This finding is particularly evident at the depths between 727 and 2127

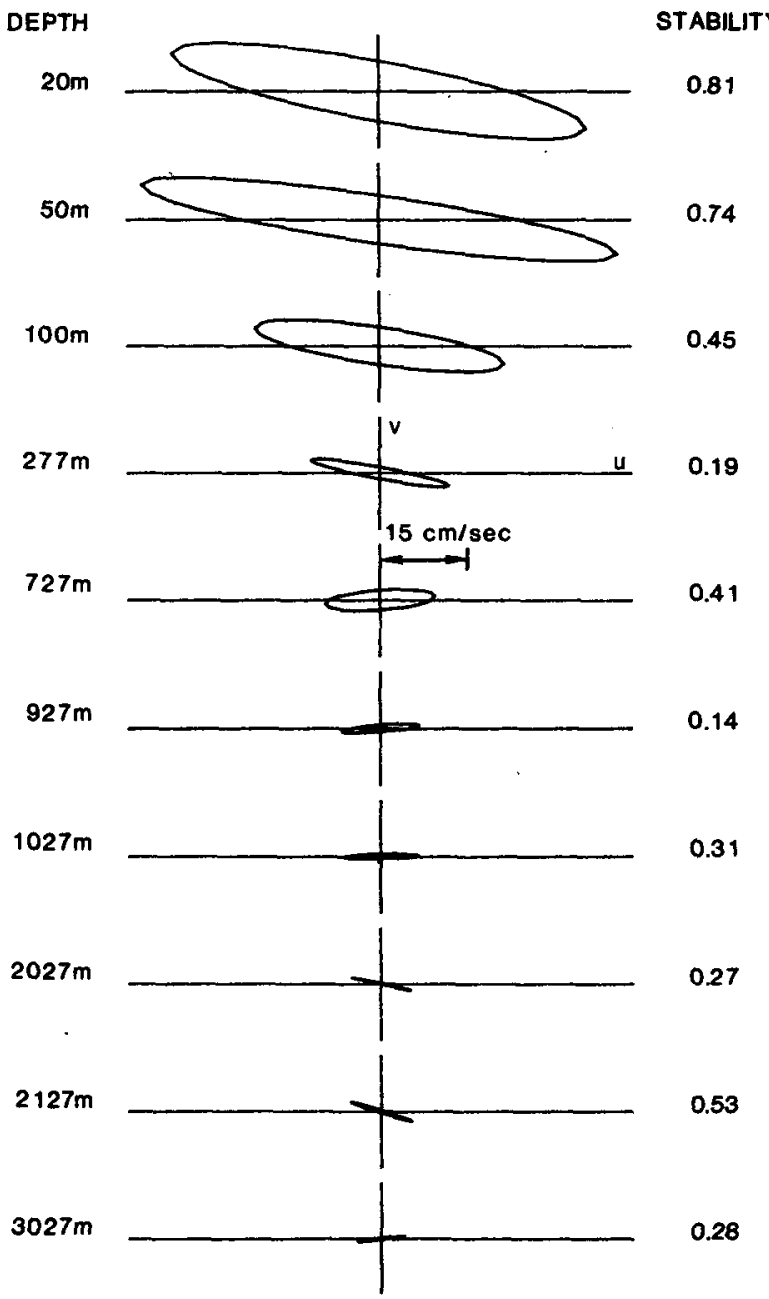

FIG. 3. Low-pass filtered velocity hodographs at each of the ten depths of record. The $90 \%$ significance level on ellipse stability is 0.25 . 


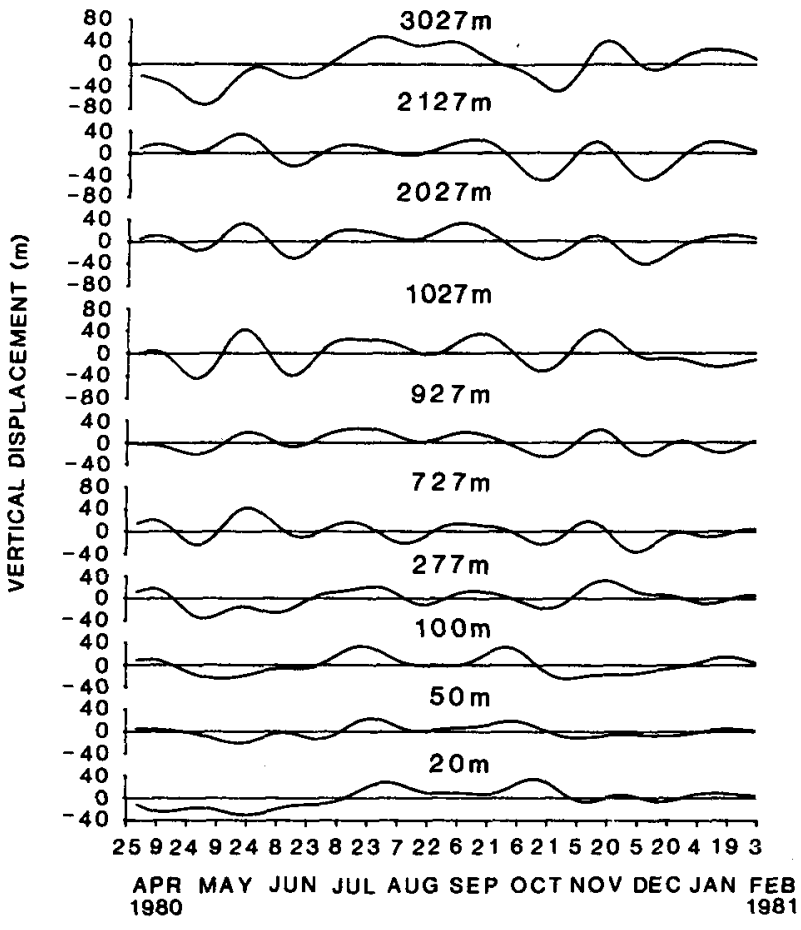

FIG. 4. Low-pass filtered vertical displacement component fluctuations at the ten depths of record.

$m$ wherein all of the fluctuations appear to be in phase. Comparing the vertical displacement time series within this depth range with the near surface east component we observe an approximate out of phase relationship which is most clearly seen between the east component at $100 \mathrm{~m}$ depth and the vertical displacement at 1027 $m$ depth. A similar statement applies for the east component at $277 \mathrm{~m}$ and vertical displacement at $2027 \mathrm{~m}$ with the agreement diminishing at further separations. These observations suggest that the vertical displacement variability has a relatively simple vertical structure and that there is a relationship between this structure and the near surface east component.

\section{Coherence analysis}

The coherence-squared and phase between each variable with itself at the different depths and between the different variables at all combinations of depths were calculated using a central frequency and bandwidth of $5.83 \times 10^{-4}$ cycles per hour (cph) and 1.17 $\times 10^{-3} \mathrm{cph}$, respectively (i.e., over all time scales greater than 36 days). The resulting degrees of freedom is 17 and the corresponding $90 \%$ significance level for the null hypothesis on coherence-squared is 0.25 (Amos and Koopmans 1963).

Table 1 shows the east component coherence squared and phase (in fractions of $\pi$ radians). Of the 45 different combinations of depths, 18 are above the significance level (as indicated by italic). The record at $20 \mathrm{~m}$ is coherent and in phase with the records at 50 and $100 \mathrm{~m}$ while it is coherent and approximately $\pi$ radians out of phase with records at 2027,2127 and $3027 \mathrm{~m}$. Similarly the record at $50 \mathrm{~m}$ is coherent and in phase with the record at $100 \mathrm{~m}$ while it is coherent and approximately $\pi$ radians out of phase with the three bottom-most depths. Records at 100 and $277 \mathrm{~m}$ show $\pi$ radian out of phase coherence with $3027 \mathrm{~m}$. All other coherent pairs are either in phase or approximately $\pi$ radians out of phase. With the exception of the three points noted by an asterisk, the coherency structure for the east component in Table 1 suggests that a nodal point is crossed at mid-depth.

For the north component (not shown) only 12 of the 45 combinations are above significance level, and seven of these are nearest-neighbor pairs. At these low frequencies the north component is generally incoherent over the entire water column with the exception of records at 100 and $277 \mathrm{~m}$, which shows some coherence with deeper records but with no consistent phase relation.

Table 2 shows the vertical displacement coherency. This is the most coherent of the three variables with 27 out of 45 combinations above the significance level. The most consistent block occurs at a depth of $727 \mathrm{~m}$ and below where with only two exceptions the records are all coherent and in phase. The record at $277 \mathrm{~m}$ is coherent and in phase with those at 927, 1027 and $3027 \mathrm{~m}$. Records at shallower depths also exhibit considerable coherence, however the phase structure is not as consistent.

Between the north and east components over all combinations of depths, only 11 out of the $100 \mathrm{com}$ binations are above the significance level which is essentially the null hypothesis. East and north components are therefore incoherent with the exception of the 20 and $50 \mathrm{~m}$ depths as evident in the hodographs of Fig. 3.

The north component is similarly incoherent with vertical displacement. Only 20 out of the 100 combinations are above the significance level. These were grouped such that the 20,50 and $100 \mathrm{~m}$ north component fluctuations appeared coherent but without any specific phase preference with the vertical displacement at several depths. The most conspicuous feature however was the absence of any coherence between the north component and the vertical displacement below $727 \mathrm{~m}$.

Table 3 shows the coherence between the east component and vertical displacement. This combination of different variables is the most coherent with 34 out of the 100 combinations above the significance level. With the exception of three points denoted by asterisks, a very consistent set of patterns emerge. Where coherent the east components above $277 \mathrm{~m}$ are approximately $\pi$ radians out of phase with the vertical displacement over the water column. No coherence is observed between the east components at either 927 or 
TABLE 1. Coherence-squared (upper) and phase (lower) between east components of velocity calculated over all depth pairs. Phase is in fractions of $\pi$ radians and those with coherence-squared above the null hypothesis are in italic.

\begin{tabular}{|c|c|c|c|c|c|c|c|c|c|c|}
\hline \multirow{2}{*}{$\begin{array}{c}\text { Depth } \\
\text { (meters) }\end{array}$} & \multicolumn{10}{|c|}{ Depth (meters) } \\
\hline & 20 & 50 & 100 & 277 & 727 & 927 & 1027 & 2027 & 2127 & 3027 \\
\hline 20 & $\begin{array}{l}1.00 \\
0.0\end{array}$ & $\begin{array}{l}0.84 \\
0.0\end{array}$ & $\begin{array}{l}0.52 \\
0.0\end{array}$ & $\begin{array}{l}0.13 \\
-0.2\end{array}$ & $\begin{array}{l}0.27^{*} \\
0.7\end{array}$ & $\begin{array}{l}0.12 \\
0.3\end{array}$ & $\begin{array}{l}0.05 \\
0.0\end{array}$ & $\begin{array}{l}0.41 \\
0.8\end{array}$ & $\begin{array}{l}0.35 \\
0.9\end{array}$ & $\begin{array}{c}0.26 \\
-1.0\end{array}$ \\
\hline 50 & & $\begin{array}{l}1.00 \\
0.0\end{array}$ & $\begin{array}{l}0.30 \\
0.1\end{array}$ & $\begin{array}{l}0.24 \\
-0.3\end{array}$ & $\begin{array}{l}0.12 \\
0.8\end{array}$ & $\begin{array}{l}0.21 \\
0.3\end{array}$ & $\begin{array}{l}0.12 \\
0.1\end{array}$ & $\begin{array}{l}0.44 \\
0.9\end{array}$ & $\begin{array}{l}0.45 \\
0.9\end{array}$ & $\begin{array}{l}0.26 \\
1.0\end{array}$ \\
\hline 100 & & & $\begin{array}{l}1.00 \\
0.0\end{array}$ & $\begin{array}{l}0.11 \\
0.2\end{array}$ & $\begin{array}{l}0.24 \\
0.5\end{array}$ & $\begin{array}{l}0.05 \\
0.0\end{array}$ & $\begin{array}{c}0.02 \\
-0.3\end{array}$ & $\begin{array}{l}0.15 \\
0.6\end{array}$ & $\begin{array}{l}0.09 \\
0.8\end{array}$ & $\begin{array}{r}0.51 \\
-0.9\end{array}$ \\
\hline 277 & & & & $\begin{array}{l}1.00 \\
0.0\end{array}$ & $\begin{array}{c}0.00 \\
-0.7\end{array}$ & $\begin{array}{r}0.12 \\
-1.0\end{array}$ & $\begin{array}{c}0.00 \\
-0.1\end{array}$ & $\begin{array}{c}0.09 \\
-0.8\end{array}$ & $\begin{array}{c}0.21 \\
-0.8\end{array}$ & $\begin{array}{l}0.26 \\
1.0\end{array}$ \\
\hline 727 & & & & & $\begin{array}{l}1.00 \\
0.0\end{array}$ & $\begin{array}{l}0.12 \\
0.1\end{array}$ & $\begin{array}{l}0.13 \\
0.4\end{array}$ & $\begin{array}{l}0.50^{*} \\
-0.1\end{array}$ & $\begin{array}{l}0.33^{*} \\
-0.1\end{array}$ & $\begin{array}{l}0.08 \\
0.6\end{array}$ \\
\hline 927 & & & & & & $\begin{array}{l}1.00 \\
0.0\end{array}$ & $\begin{array}{l}0.63 \\
0.0\end{array}$ & $\begin{array}{c}0.01 \\
-0.4\end{array}$ & $\begin{array}{c}0.01 \\
-0.8\end{array}$ & $\begin{array}{r}0.06 \\
-0.7\end{array}$ \\
\hline 1027 & & & & & & & $\begin{array}{l}1.00 \\
0.0\end{array}$ & $\begin{array}{l}0.17 \\
-0.7\end{array}$ & $\begin{array}{l}0.27 \\
-0.8\end{array}$ & $\begin{array}{c}0.09 \\
-0.8\end{array}$ \\
\hline 2027 & & & & & & & & $\begin{array}{l}1.00 \\
0.0\end{array}$ & $\begin{array}{l}0.82 \\
-0.1\end{array}$ & $\begin{array}{l}0.21 \\
0.1\end{array}$ \\
\hline 2127 & & & & & & & & & $\begin{array}{l}1.00 \\
0.0\end{array}$ & $\begin{array}{l}0.32 \\
0.1\end{array}$ \\
\hline 3027 & & & & & & & & & & $\begin{array}{l}1.00 \\
0.0\end{array}$ \\
\hline
\end{tabular}

TABLE 2. Coherence-squared (upper) and phase (lower) between vertical displacement calculated over all depth pairs. Phase is in fractions of $\pi$ radians and those with coherence-squared above the null hypothesis are in italic.

\begin{tabular}{|c|c|c|c|c|c|c|c|c|c|c|}
\hline \multirow{2}{*}{$\begin{array}{c}\text { Depth } \\
\text { (meters) }\end{array}$} & \multicolumn{10}{|c|}{ Depth (meters) } \\
\hline & 20 & 50 & 100 & 277 & 727 & 927 & 1027 & 2027 & 2127 & 3027 \\
\hline 20 & $\begin{array}{l}1.00 \\
0.0\end{array}$ & $\begin{array}{l}0.67 \\
0.1\end{array}$ & $\begin{array}{l}0.63 \\
0.3\end{array}$ & $\begin{array}{l}0.17 \\
0.01\end{array}$ & $\begin{array}{l}0.29 \\
0.8\end{array}$ & $\begin{array}{l}0.35 \\
0.5\end{array}$ & $\begin{array}{l}0.07 \\
0.5\end{array}$ & $\begin{array}{l}0.09 \\
0.6\end{array}$ & $\begin{array}{l}0.16 \\
0.8\end{array}$ & $\begin{array}{l}0.34 \\
0.2\end{array}$ \\
\hline 50 & & $\begin{array}{l}1.00 \\
0.0\end{array}$ & $\begin{array}{l}0.88 \\
0.1\end{array}$ & $\begin{array}{l}0.17 \\
0.2\end{array}$ & $\begin{array}{l}0.28 \\
0.6\end{array}$ & $\begin{array}{l}0.44 \\
0.4\end{array}$ & $\begin{array}{l}0.14 \\
0.5\end{array}$ & $\begin{array}{l}0.23 \\
0.4\end{array}$ & $\begin{array}{l}0.17 \\
0.5\end{array}$ & $\begin{array}{l}0.41 \\
0.3\end{array}$ \\
\hline 100 & & & $\begin{array}{l}1.00 \\
0.0\end{array}$ & $\begin{array}{l}0.15 \\
0.1\end{array}$ & $\begin{array}{l}0.17 \\
0.4\end{array}$ & $\begin{array}{l}0.31 \\
0.3\end{array}$ & $\begin{array}{l}0.09 \\
0.3\end{array}$ & $\begin{array}{l}0.16 \\
0.3\end{array}$ & $\begin{array}{l}0.13 \\
0.4\end{array}$ & $\begin{array}{l}0.28 \\
0.1\end{array}$ \\
\hline 277 & & & & $\begin{array}{l}1.00 \\
0.0\end{array}$ & $\begin{array}{l}0.16 \\
0.5\end{array}$ & $\begin{array}{l}0.37 \\
0.2\end{array}$ & $\begin{array}{l}0.44 \\
0.1\end{array}$ & $\begin{array}{l}0.08 \\
0.2\end{array}$ & $\begin{array}{l}0.02 \\
0.3\end{array}$ & $\begin{array}{l}0.53 \\
0.0\end{array}$ \\
\hline 727 & & & & & $\begin{array}{l}1.00 \\
0.0\end{array}$ & $\begin{array}{c}0.58 \\
-0.1\end{array}$ & $\begin{array}{c}0.41 \\
-0.1\end{array}$ & $\begin{array}{l}0.58 \\
0.0\end{array}$ & $\begin{array}{l}0.54 \\
0.1\end{array}$ & $\begin{array}{l}0.15 \\
-0.4\end{array}$ \\
\hline 927 & & & & & & $\begin{array}{l}1.00 \\
0.0\end{array}$ & $\begin{array}{l}0.69 \\
0.0\end{array}$ & $\begin{array}{l}0.65 \\
0.1\end{array}$ & $\begin{array}{l}0.50 \\
0.1\end{array}$ & $\begin{array}{l}0.59 \\
-0.2\end{array}$ \\
\hline 1027 & & & & & & & $\begin{array}{l}1.00 \\
0.0\end{array}$ & $\begin{array}{l}0.56 \\
0.1\end{array}$ & $\begin{array}{l}0.40 \\
0.2\end{array}$ & $\begin{array}{r}0.41 \\
-0.1\end{array}$ \\
\hline 2027 & & & & & & & & $\begin{array}{l}1.00 \\
0.0\end{array}$ & $\begin{array}{l}0.84 \\
0.0\end{array}$ & $\begin{array}{l}0.27 \\
-0.1\end{array}$ \\
\hline 2127 & & & & & & & & & $\begin{array}{l}1.00 \\
0.0\end{array}$ & $\begin{array}{l}0.12 \\
-0.2\end{array}$ \\
\hline 3027 & & & & & & & & & & $\begin{array}{l}1.00 \\
0.0\end{array}$ \\
\hline
\end{tabular}


TABLE 3. Coherence-squared (upper) and phase (lower) between the east component of velocity (columns) and vertical displacement (rows) calculated over all depth pairs. Phase is in fractions of $\pi$ radians and those with coherence-squared above the null hypothesis are in italic.

\begin{tabular}{|c|c|c|c|c|c|c|c|c|c|c|}
\hline \multirow{2}{*}{$\begin{array}{l}\text { Depth } \\
\text { (meters) }\end{array}$} & & \multicolumn{2}{|c|}{ Depth (meters) } & \multirow[b]{2}{*}{1027} & \multirow[b]{2}{*}{2027} & \multirow[b]{2}{*}{2127} & \multirow[b]{2}{*}{3027} \\
\hline & 20 & 50 & 100 & 277 & 727 & 927 & & & & \\
\hline 20 & $\begin{array}{l}0.31 \\
0.8\end{array}$ & $\begin{array}{l}0.23 \\
0.8\end{array}$ & $\begin{array}{l}0.20 \\
0.8\end{array}$ & $\begin{array}{l}0.67 \\
0.9\end{array}$ & $\begin{array}{l}0.23 \\
-0.5\end{array}$ & $\begin{array}{c}0.32 \\
-0.8\end{array}$ & $\begin{array}{c}0.36 \\
-0.8\end{array}$ & $\begin{array}{l}0.10 \\
-0.5\end{array}$ & $\begin{array}{c}0.08 \\
-0.3\end{array}$ & $\begin{array}{l}0.49 \\
1.0\end{array}$ \\
\hline 50 & $\begin{array}{l}0.24 \\
1.0\end{array}$ & $\begin{array}{l}0.05 \\
0.8\end{array}$ & $\begin{array}{l}0.04 \\
0.8\end{array}$ & $\begin{array}{l}0.69 \\
0.9\end{array}$ & $\begin{array}{l}0.11 \\
-0.4\end{array}$ & $\begin{array}{c}0.13 \\
-0.7\end{array}$ & $\begin{array}{c}0.22 \\
-0.9\end{array}$ & $\begin{array}{l}0.02 \\
-0.4\end{array}$ & $\begin{array}{c}0.06 \\
-0.1\end{array}$ & $\begin{array}{l}0.38 \\
1.0\end{array}$ \\
\hline 100 & $\begin{array}{l}0.50^{*} \\
0.6\end{array}$ & $\begin{array}{l}0.57 \\
0.7\end{array}$ & $\begin{array}{l}0.64 \\
0.8\end{array}$ & $\begin{array}{l}0.53 \\
0.9\end{array}$ & $\begin{array}{l}0.35 \\
-0.7\end{array}$ & $\begin{array}{l}0.43 \\
-0.9\end{array}$ & $\begin{array}{r}0.35 \\
-1.0\end{array}$ & $\begin{array}{l}0.15 \\
-0.8\end{array}$ & $\begin{array}{l}0.13 \\
-0.7\end{array}$ & $\begin{array}{l}0.41 \\
0.9\end{array}$ \\
\hline 277 & $\begin{array}{c}0.04 \\
-0.1\end{array}$ & $\begin{array}{l}0.13 \\
0.4\end{array}$ & $\begin{array}{l}0.23 \\
0.5\end{array}$ & $\begin{array}{l}0.25 \\
-0.8\end{array}$ & $\begin{array}{l}0.07 \\
0.8\end{array}$ & $\begin{array}{l}0.03 \\
0.7\end{array}$ & $\begin{array}{c}0.18 \\
-0.9\end{array}$ & $\begin{array}{l}0.04 \\
0.9\end{array}$ & $\begin{array}{l}0.08 \\
0.8\end{array}$ & $\begin{array}{c}0.05 \\
-1,0\end{array}$ \\
\hline 727 & $\begin{array}{l}0.48 \\
0.1\end{array}$ & $\begin{array}{l}0.35 \\
0.1\end{array}$ & $\begin{array}{l}0.29 \\
0.2\end{array}$ & $\begin{array}{l}0.15 \\
0.4\end{array}$ & $\begin{array}{c}0.22 \\
-1.0\end{array}$ & $\begin{array}{l}0.32 \\
-0.7\end{array}$ & $\begin{array}{l}0.16 \\
0.6\end{array}$ & $\begin{array}{l}0.09 \\
0.8\end{array}$ & $\begin{array}{l}0.25 \\
1.0\end{array}$ & $\begin{array}{l}0.33 \\
0.4\end{array}$ \\
\hline 927 & $\begin{array}{l}0.12 \\
0.1\end{array}$ & $\begin{array}{l}0.05 \\
0.1\end{array}$ & $\begin{array}{l}0.03 \\
0.2\end{array}$ & $\begin{array}{l}0.07 \\
0.4\end{array}$ & $\begin{array}{c}0.12 \\
-1.0\end{array}$ & $\begin{array}{c}0.08 \\
-0.7\end{array}$ & $\begin{array}{l}0.12 \\
0.6\end{array}$ & $\begin{array}{l}0.06 \\
0.8\end{array}$ & $\begin{array}{l}0.02 \\
1.0\end{array}$ & $\begin{array}{l}0.03 \\
0.4\end{array}$ \\
\hline 1027 & $\begin{array}{l}0.22 \\
-0.9\end{array}$ & $\begin{array}{l}0.09 \\
-0.8\end{array}$ & $\begin{array}{l}0.13 \\
-0.5\end{array}$ & $\begin{array}{l}0.05 \\
0.8\end{array}$ & $\begin{array}{c}0.09 \\
-0.7\end{array}$ & $\begin{array}{l}0.09 \\
-0.7\end{array}$ & $\begin{array}{c}0.05 \\
-1.0\end{array}$ & $\begin{array}{c}0.14 \\
-0.7\end{array}$ & $\begin{array}{c}0.08 \\
-0.9\end{array}$ & $\begin{array}{l}0.08 \\
-0.9\end{array}$ \\
\hline 2027 & $\begin{array}{l}0.44 \\
0.1\end{array}$ & $\begin{array}{l}0.13 \\
0.0\end{array}$ & $\begin{array}{l}0.11 \\
0.1\end{array}$ & $\begin{array}{l}0.19 \\
0.1\end{array}$ & $\begin{array}{l}0.17 \\
-0.9\end{array}$ & $\begin{array}{l}0.04 \\
0.7\end{array}$ & $\begin{array}{l}0.01 \\
0.8\end{array}$ & $\begin{array}{l}0.09 \\
-0.6\end{array}$ & $\begin{array}{l}0.27^{*} \\
-0.7\end{array}$ & $\begin{array}{l}0.25 \\
0.1\end{array}$ \\
\hline 2127 & $\begin{array}{l}0.32 \\
0.1\end{array}$ & $\begin{array}{l}0.08 \\
0.0\end{array}$ & $\begin{array}{l}0.07 \\
0.1\end{array}$ & $\begin{array}{l}0.28 \\
0.1\end{array}$ & $\begin{array}{c}0.04 \\
-0.9\end{array}$ & $\begin{array}{l}0.06 \\
0.7\end{array}$ & $\begin{array}{l}0.07 \\
0.8\end{array}$ & $\begin{array}{c}0.10 \\
-0.6\end{array}$ & $\begin{array}{c}0.11 \\
-0.7\end{array}$ & $\begin{array}{l}0.42 \\
0.1\end{array}$ \\
\hline 3027 & $\begin{array}{l}0.23 \\
-0.4\end{array}$ & $\begin{array}{l}0.50^{*} \\
-0.5\end{array}$ & $\begin{array}{c}0.51 \\
-0.3\end{array}$ & $\begin{array}{c}0.39 \\
-0.1\end{array}$ & $\begin{array}{l}0.09 \\
0.0\end{array}$ & $\begin{array}{c}0.33 \\
-0.1\end{array}$ & $\begin{array}{c}0.22 \\
-0.1\end{array}$ & $\begin{array}{c}0.31 \\
-0.2\end{array}$ & $\begin{array}{l}0.20 \\
-0.2\end{array}$ & 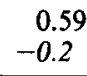 \\
\hline
\end{tabular}

$1027 \mathrm{~m}$ and the vertical displacements at any depth and where the east component at $727 \mathrm{~m}$ is coherent with vertical displacement over depth there is no consistent phase relationship. At $2027 \mathrm{~m}$ and below, where the east component and the vertical displacement are coherent, the phase relationship is approximately in phase.

The coherence analysis findings may be summarized as follows. Between variables with themselves the north component is generally incoherent; the east component phase reverses sign across $1027 \mathrm{~m}$ from in phase to approximately $\pi$ radians out of phase suggesting a nodal point; and the vertical displacement is the most coherent variable especially below $727 \mathrm{~m}$ where all coherent pairs are in phase. Between each variable with the others the north component is incoherent with the east component except near the surface; there is an absence of north component coherence with displacement below $727 \mathrm{~m}$; and three separate regions of east component/vertical displacement phase relationships exists: 1) the upper portion of the water column where they are approximately $\pi$ radians out of phase, 2) a transition region at mid-depth, and 3) the lower portion of the water column where they are in phase. These findings are consistent with a first baroclinic vertical mode for the east component of velocity and temperature (vertical displacement) fluctuations over the time scales considered.

\section{Empirical orthogonal function analysis}

Empirical orthogonal functions (EOFs) in the time domain [e.g., Wallace and Dickinson 1972] were determined separately for each of the velocity components and the vertical displacement by solving for the eigenvalues and eigenvectors of their respective covariance matrices over the ten record depths. The formulation is the same as that used by Weisberg et al. (1987a) with the units contained in the eigenvectors and the modal projection time series orthonormal.

Table 4 lists the variance for the first four modes and their percent of total variance for the east and north velocity components and the vertical displacement field. The corresponding eigenvectors of the first two

TABLE 4. The variance associated with each of the first five EOF modes and their percent of total variance.

\begin{tabular}{|c|c|c|c|c|c|c|}
\hline \multirow[b]{2}{*}{ Mode } & \multicolumn{2}{|c|}{ East component } & \multicolumn{2}{|c|}{ North component } & \multicolumn{2}{|c|}{$\begin{array}{c}\text { Vertical } \\
\text { displacement }\end{array}$} \\
\hline & $\begin{array}{l}\text { Variance } \\
\left(\mathrm{cm} \mathrm{s}^{-1}\right)^{2}\end{array}$ & Percent & $\begin{array}{l}\text { Variance } \\
\left(\mathrm{cm} \mathrm{s}^{-1}\right)^{2}\end{array}$ & Percent & $\begin{array}{l}\text { Variance } \\
(\mathrm{m})^{2}\end{array}$ & Percent \\
\hline 1 & 2680 & 82.9 & 265 & 58.7 & 1850 & 57.1 \\
\hline 2 & 266 & 8.2 & 84 & 18.7 & 842 & 26.0 \\
\hline 3 & 100 & 3.1 & 37 & 8.2 & $228^{\circ}$ & 7.0 \\
\hline 4 & 89 & 2.7 & 29 & 6.4 & 137 & 4.2 \\
\hline 5 & 49 & 1.5 & 22 & 4.8 & 86 & 2.7 \\
\hline
\end{tabular}


modes for each of the variables are given in Fig. 5. For the east component the first mode has a maximum at the surface, which is out of phase with the motions at $2027 \mathrm{~m}$ and below. Multiple zero crossings between 277 and $2027 \mathrm{~m}$ are attributed to the one record at $727 \mathrm{~m}$, which was also the only inconsistent point observed in the first column of Table 1 . The amplitude of the second mode is comparable to that of the first mode only at 50 and $100 \mathrm{~m}$, between which occurs a zero crossing. For the north component the first two modes are of comparable magnitude near the surface and the second one is largest at depth. For the vertical displacement the first mode is in phase over the entire water column with nearly zero amplitude at $20 \mathrm{~m}$. The second mode has a relative maximum at $20 \mathrm{~m}$ and two zero crossings over the water column.

The coherence-squared between the modal projection time series and the data at the individual depths (using the same bandwidth as in section 3 ) offers some clarification as shown in Fig. 6. For the east component the first mode is coherent with the data above $100 \mathrm{~m}$, incoherent with the data at mid-depth, and again coherent with the data at $2027 \mathrm{~m}$ and below while the second mode is generally incoherent with the data except at $100 \mathrm{~m}$. For the north component the first mode is coherent with the data above $100 \mathrm{~m}$ while the second mode appears coherent at both $100 \mathrm{~m}$ and below 2027 $\mathrm{m}$. Similar coherence was noted in section 3 but without any clear phase relationship. For the vertical displacement the first mode is coherent with the data at all depths excepting $20 \mathrm{~m}$, while the second mode is coherent with the data at 20,50 and $727 \mathrm{~m}$ and to a much lesser extent over the water column. Both the vertical distributions of the amplitude and phase for the first EOF modes and the coherence between these modes with the data at the individual depths are again suggestive of a first baroclinic mode for the east component and vertical displacement.

\section{Dynamical mode decomposition}

Given the suggestion of the previous two sections, how well can the data be described by the ocean's vertical modes? Figure 7 shows a buoyancy frequency profile determined from the average of several deep CTD casts made in the study area during July 1979 (S. P. Hayes, personal communication, 1984). This was used to calculate the ocean's dynamical modes by solving the vertical structure equation for the vertical velocity component:

$$
F_{n}^{\prime \prime}(z)+\frac{N^{2}(z)}{C_{n}^{2}} F_{n}(z)=0
$$

where $F_{n}(z)$ are the eigenfunctions for the $n$th mode, $C_{n}$ are the eigenvalues, and $N(z)$ is the buoyancy. The free surface boundary condition used to allow for a barotropic mode is

$$
F_{n}^{\prime}(0)-\frac{g}{C_{n}^{2}} F_{n}(0)=0
$$

where $g$ is the gravitational acceleration and the bottom boundary condition is $F_{n}=0$. A finite difference calculation was utilized to determine the eigenfunctions and eigenvalues by starting at the surface and using a trial and error method to match the bottom boundary
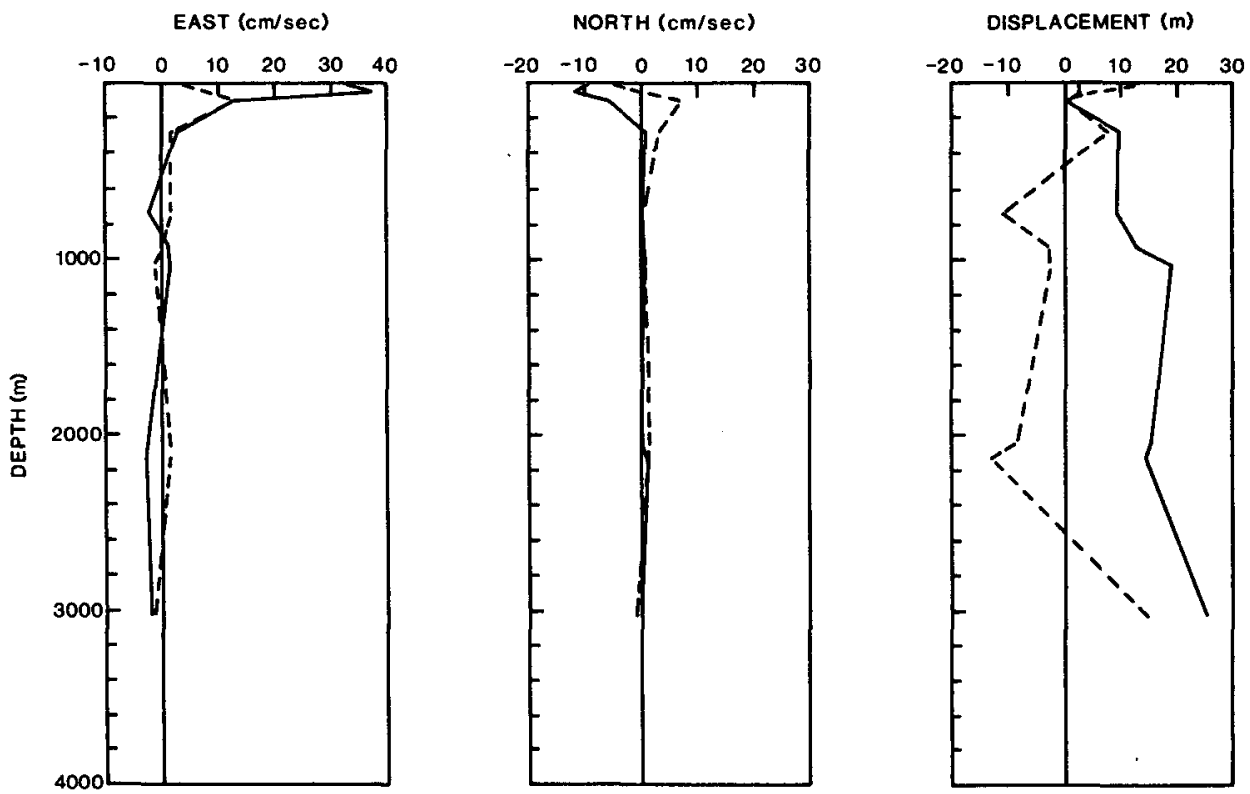

FIG. 5. First mode (solid line) and second mode (dashed line) EOFs computed for the east and north velocity components and the vertical displacement time series of Figs. 1, 2 and 4, respectively. 

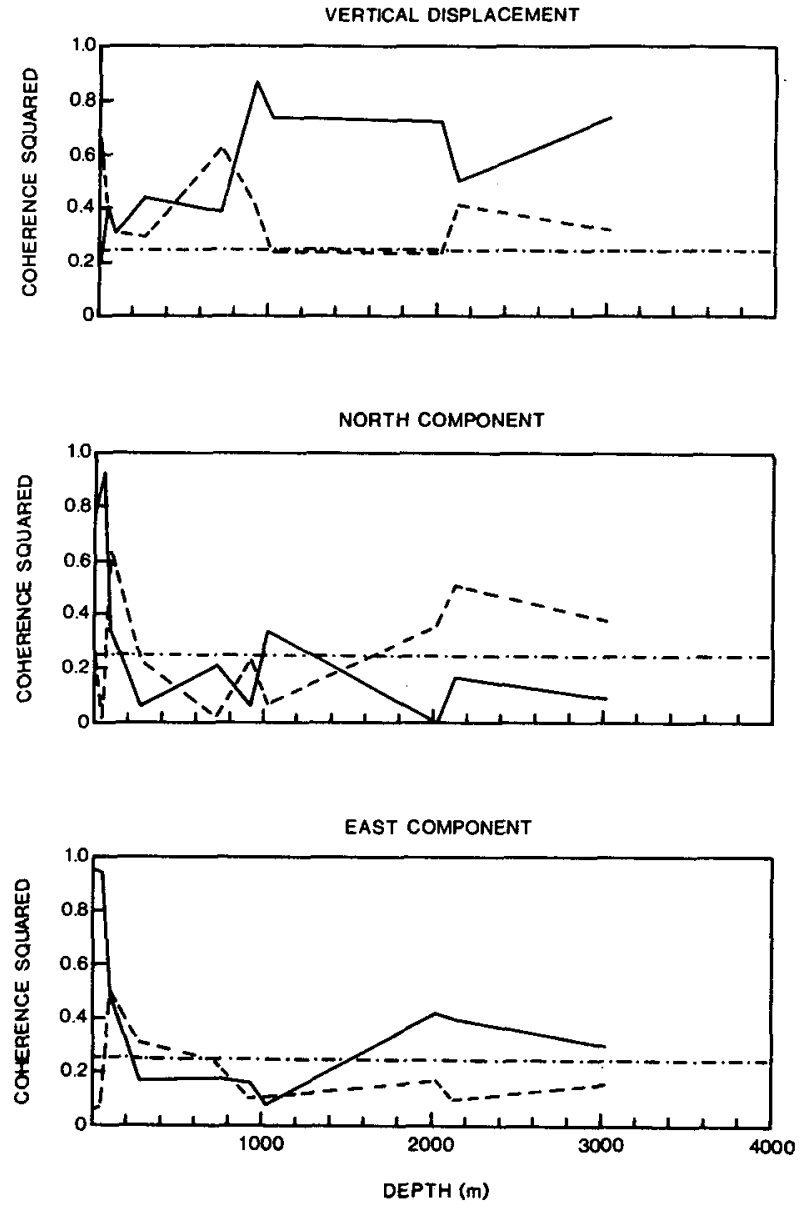

FIG. 6. The coherence-squared between the first two EOF modes and the data at each of the individual depths. Solid and dashed lines correspond to the first and second EOF modes, respectively. The $90 \%$ significance level on coherence squared is given by the horizontal line.

condition. The eigenfunctions proportional to the vertical velocity component were then normalized and differentiated to obtain eigenfunctions proportional to the horizontal velocity components. The resulting vertical and horizontal velocity component eigenfunctions for the barotropic and the first three baroclinic modes along with the corresponding baroclinic mode eigenvalues are given in Fig. 8 . These are essentially the same as those used in Hayes and Halpern (1984) computed with a slightly different buoyancy frequency profile.

The horizontal velocity components and the proxy for vertical displacement at the ten depths were projected onto the barotropic and the first three baroclinic modes by minimizing the mean-squared error between the data and a linear combination of the modes summed over the ten depths using the formulation given in Weisberg et al. (1987b). The resulting modalprojection time series for each of the four dynamical modes are shown in Fig. 9. The units are contained in the modal projection time series and to obtain the linear least-squares modal contribution at any specific depth the time series must be multiplied by the respective value of the eigenfunction at that depth. Several features are noteworthy. 1) On average over the water column the first baroclinic mode dominates over the other modes for the east velocity component and the vertical displacement. 2) The first baroclinic mode for the east velocity component and the vertical displacement vary approximately $\pi$ radians out of phase over the entire record length. 3) No modal preference is observed for the north velocity component nor do the north component modes show any obvious relationship to the modes of the other variables.

For a first baroclinic mode, Fig. 8 shows that the best correspondence between the east component and vertical displacement should occur when comparing the former at $100 \mathrm{~m}$ with the latter at $1027 \mathrm{~m}$ since these are the relative maximum positions. Figure 10 shows the individual modes and their cumulative summations compared with the data for the east velocity component at $100 \mathrm{~m}$ and the vertical displacement at $1027 \mathrm{~m}$. For the east component the barotropic mode is very small and the third baroclinic mode is absent due to a zero crossing. The first baroclinic mode is the largest and its variations resemble those of the data. Addition of the second baroclinic mode offers a

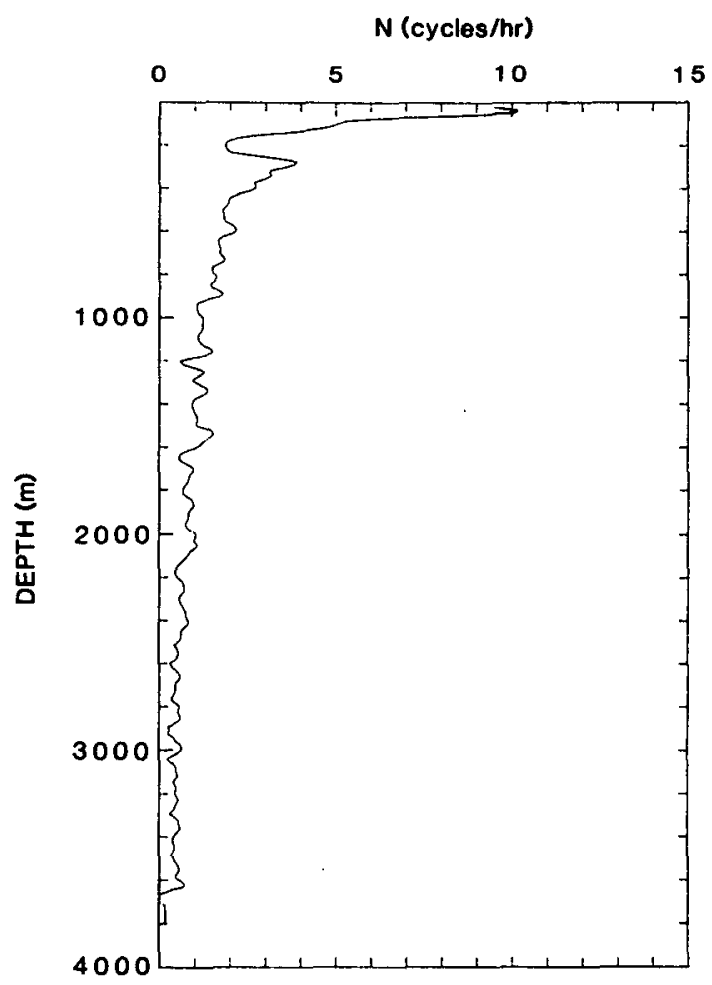

FIG. 7. Buoyancy frequency as a function of depth at $0^{\circ}, 110^{\circ} \mathrm{W}$ (S. P. Hayes, personal communication, 1984). 

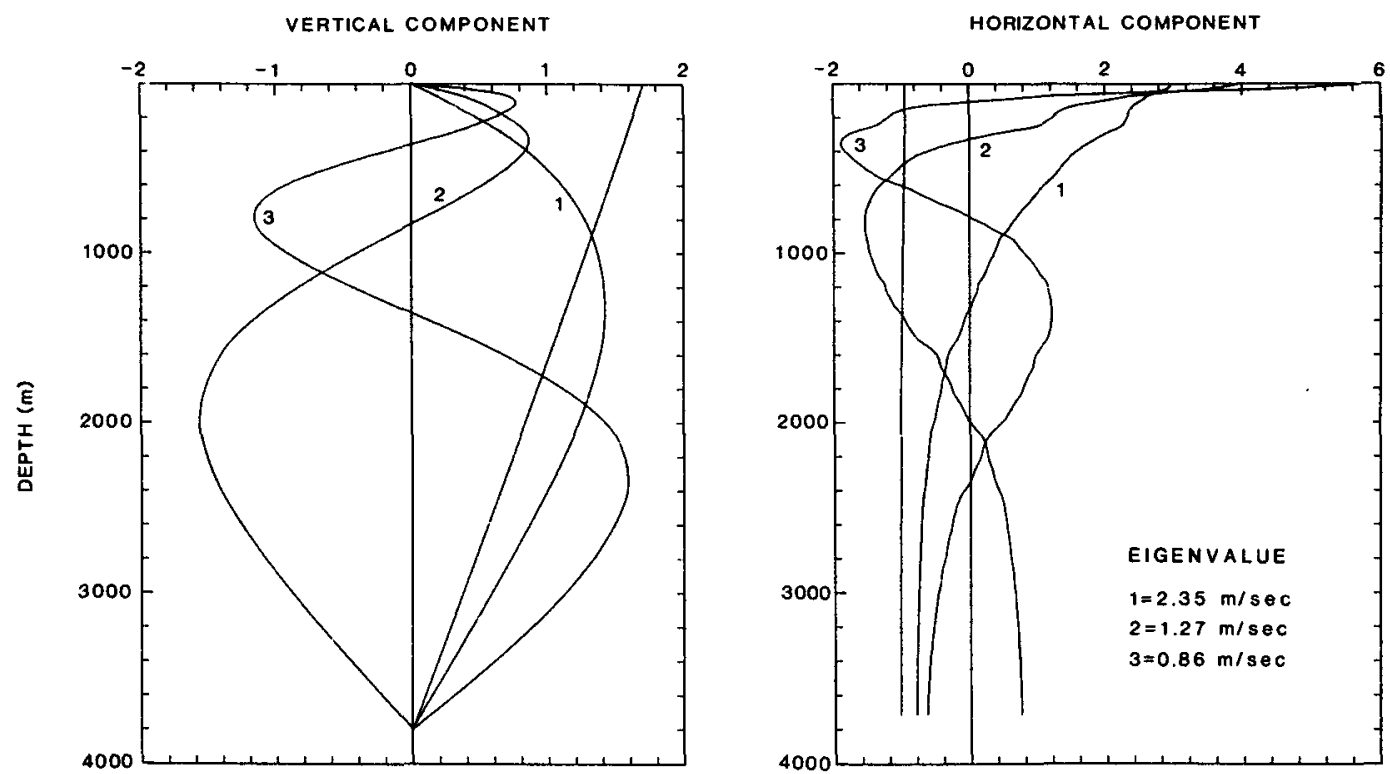

FIG. 8. The nondimensional vertical and horizontal velocity component eigenfunctions for the barotropic and the first three baroclinic modes computed from the buoyancy frequency profile of Fig. 7 .

little improvement. All of the modes are present for the vertical displacement at $1027 \mathrm{~m}$. The first baroclinic mode is again the dominant one, and its variations closely resemble those of the data. However the barotropic mode projection is not insignificant. The origin of the barotropic mode is at the surface since it is the only mode available there for fitting to the proxy time series that is being used for vertical displacement. As recognized in section 2, the neglect of horizontal advection and nonadiabatic processes are poor assumptions near the surface. Thus the appearance of a baro- tropic mode here is probably a consequence of this as opposed to being a physical mode. Away from the surface however these assumptions are reasonable.

The results of this section are summarized in Table 5. Listed are the variance ratios between each of the individual dynamical modes with the sum over the four modes. The north velocity component shows no preference; the first baroclinic mode is the largest one for the east velocity component and the vertical displacement; and the vertical displacement has the simplest structure despite the spurious barotropic mode.

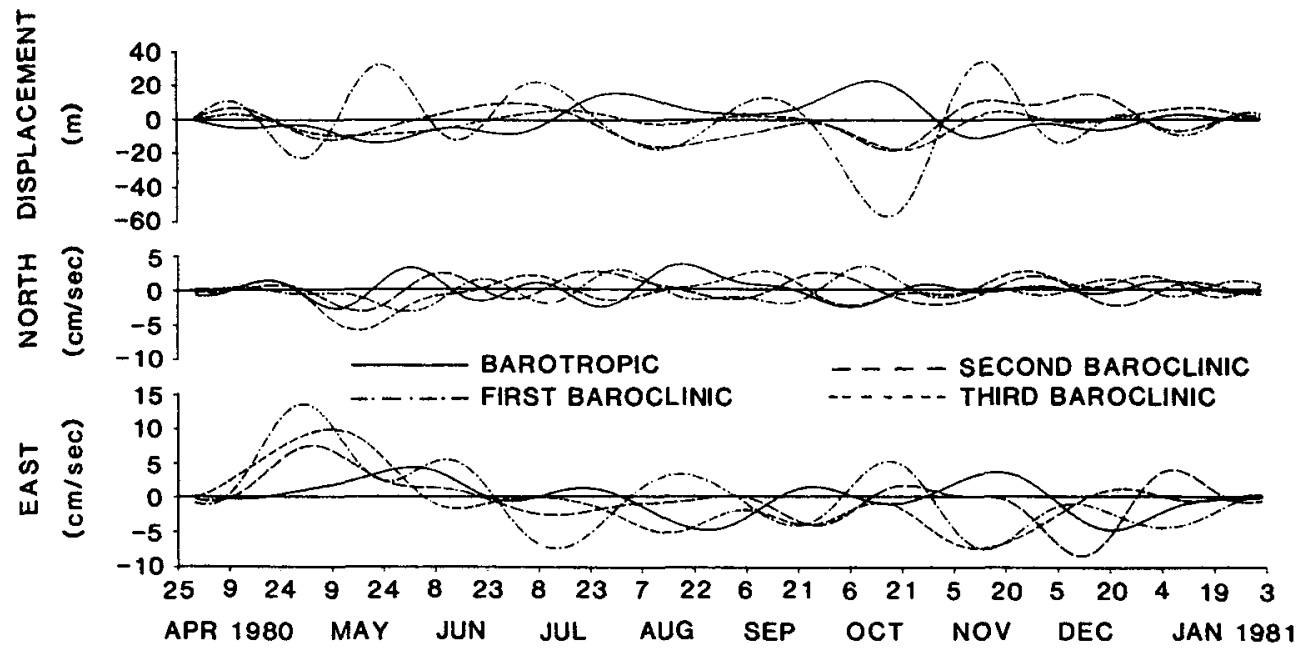

FIG. 9. Linear least-squares projections of the data onto the barotropic and first three baroclinic modes of Fig. 8 for the horizontal velocity components and the vertical displacement. 

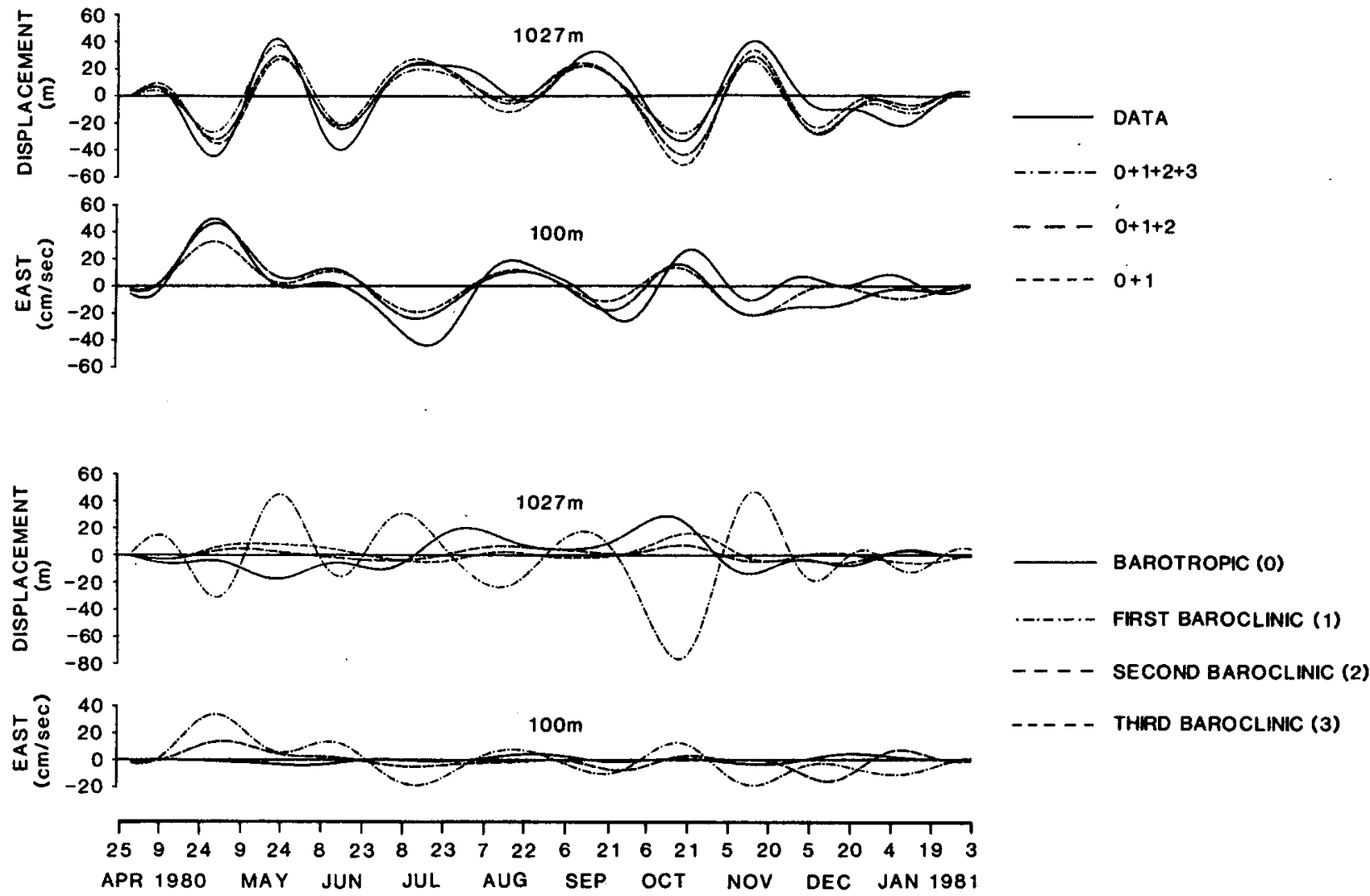

FIG. 10. The amplitudes of the individual linear least-squares fit dynamical modes and their cumulative sums relative to the data at $100 \mathrm{~m}$ for the east component and at $1027 \mathrm{~m}$ for the vertical displacement.

\section{Summary and discussion}

Ten months of horizontal velocity component and temperature data collected at ten depths on the equator near $110^{\circ} \mathrm{W}$ have been analyzed for vertical structure at fluctuation time scales longer than 36 days. Temperature was scaled by the vertical temperature gradient to obtain a proxy time series for vertical displacement assuming nonadiabatic and horizontal advection effects to be negligible. Visual inspection, coherence analysis, empirical orthogonal function analysis, and linear leastsquares dynamical mode decomposition all suggest a first baroclinic mode in the east component and vertical displacement fluctuations over the ten months of record at these time scales. The north component was

TABLE 5. The percent of variance for each of the four dynamical modes fit by linear least squares relative to their sum.

\begin{tabular}{lccc}
\hline \hline Dynamical mode & $\begin{array}{c}\text { East } \\
\text { component } \\
(\%)\end{array}$ & $\begin{array}{c}\text { North } \\
\text { component } \\
(\%)\end{array}$ & $\begin{array}{c}\text { Vertical } \\
\text { displacement } \\
(\%)\end{array}$ \\
\hline Barotropic & 9.5 & 21.6 & 14.2 \\
First baroclinic & 42.5 & 20.8 & 64.9 \\
Second baroclinic & 17.7 & 22.1 & 14.4 \\
Third baroclinic & 30.3 & 35.5 & 6.5 \\
\hline
\end{tabular}

generally unrelated with the east component or vertical displacement, and no modal preference was observed for it. While a dominant baroclinic mode existed over depth, near-surface modifications were observed for both the east component and vertical displacement.

Both the EOF and dynamical mode decompositions yield quantitative results on partition of variance among modes. However these techniques are subject to both random errors and data and model-dependent bias errors, which place their quantitative results in question. Random errors are discussed in detail by Hayes et al. (1985) for a linear least-squares dynamical mode fitting application similar to the present one. It was concluded that random errors were as large as the actual modes for mode fits utilizing data above 1000 $m$ only. While substantial improvement was obtained by adding five deep measurements, our dataset effectively has only two such deeper measurements available. Data dependent biases arise for both EOF and dynamical mode decompositions. For EOFs, the data are forced onto orthogonal data modes even though the physical modes may not be orthogonal over the data space. For the dynamical mode decompositions, the modes are dependent upon the local buoyancy frequency distribution which may change seasonally and in space such that the dynamical modes in the region 
of generation may differ from the local modes. The actual mode shapes also affect the coupling between the forcing function and the ocean. For these reasons, while we conclude that a first baroclinic mode was observed as the primary mode, we will not attempt a quantitative distribution of variance among the different modes.

In their analysis of the upper ocean data, Hayes and Halpern (1984) found that the east component at 20 and $50 \mathrm{~m}$ was correlated with local wind while the deeper currents and sea level were not. Since local wind variations may differ from the larger-scale wind field variations it is reasonable to expect surface current modifications by the local winds while the deeper currents and vertical displacement may be influenced more by the zonally integrated effects of the largerscale forcing. Thus we find better correspondence between the east velocity component fluctuations at 100 $m$ and the vertical displacement over the water column than with the east component fluctuations at 20 or 50 $\mathrm{m}$. The consistent $\pi$ radian out-of-phase relationship between the east velocity component at $100 \mathrm{~m}$ and the vertical displacement over the water column further suggests that an equatorial Kelvin wave dominates these joint fluctuations since these two components would be in phase for an equatorial Rossby wave. Therefore the observed low-frequency first baroclinicmode fluctuations are consistent with the zonally integrated effects of forcing upon the equatorial ocean occurring west of $110^{\circ} \mathrm{W}$ in accordance with previous inferences cited in section 1 .

The spurious barotropic mode found primarily in vertical displacement may be due to both horizontal advection and nonadiabatic processes inappropriately assumed to be small at 20 and $50 \mathrm{~m}$. The importance of nonadiabatic processes for the mixed layer temperature in the equatorial Pacific Ocean was clearly demonstrated by Stevenson and Niiler (1983). A similar result was also found for the equatorial Atlantic by Weisberg and Colin (1986).

Acknowledgments. This research was largely supported by the Equatorial Pacific Ocean Climate Studies Project of NOAA. Partial support for T. Y. Tang and R. H. Weisberg was also provided by the Oceanography Section, National Science Foundation under Grant OCE-8515869 and OCE-8740380.

\section{REFERENCES}

Amos, D. E., and L. H. Koopmans, 1963: Table of the distribution of the coefficient of coherence for stationary bivariate Gaussian processes. U.S. Dept. of Commerce.

Behringer, D. W., 1984: Equatorial modes in the eastern Pacific $\left(85^{\circ} \mathrm{W}\right)$. J. Geophys. Res., 89, 3729-3731.
Busalacchi, A. J., K. Takeuchi and J. J. O'Brien, 1983: On the interannual wind-driven response of the tropical Pacific Ocean. Hydrodynamics of the Equatorial Ocean: Proc. 14th Int. Liege Colloq. on Ocean Hydrodynamics, C. J. Nihoul, Ed. pp. 155195, Elsevier.

Cane, M., and E. S. Sarachik, 1976: Forced baroclinic ocean motions I. The linear equatorial unbounded case. J. Mar. Res., 34, 629665.

Eriksen, C. C., 1982: Equatorial wave vertical modes observed in a western Pacific Island array. J. Phys. Oceanogr., 12, 1206-1227.

- M. B. Blumenthal, S. P. Hayes and P. Ripa, 1983: Wind-generated equatorial Kelvin waves observed across the Pacific Ocean. J. Phys. Oceanogr., 13, 1622-1640.

Halpern, D., 1987a: Comparison of upper ocean VACM and VMCM dyad observations in the equatorial Pacific. J. Atmos. Oceanic Technol., 4, 84-93.

__ 1987b: Observations of annual and El Nino thermal and flow variations at $0^{\circ}, 110^{\circ} \mathrm{W}$ and $0^{\circ}, 95^{\circ} \mathrm{W}$ during $1980-1985 . J$. Geophys. Res., 92, 8197-8212.

— , and R. D. Pillsbury, 1976: Near surface moored current meter measurements. Mar. Technol. Soc. J., 10, 31-38.

Hayes, S. P., and D. Halpern, 1984: Correlation of current and sea level in the eastern equatorial Pacific. J. Phys. Oceanogr., 14, $811-824$.

—, P. Ripa and L. J. Mangum, 1985: On resolving vertical modes with observational data. J. Geophys. Res., 90, 7227-7234.

Katz, E. J., 1987: Equatorial Kelvin waves in the Atlantic. J. Geophys. Res., 92, 1894-1898.

Knox, R. A., and D. Halpern, 1982: Long range Kelvin wave propagation of transport variations in Pacific Ocean equatorial cur. rents. J. Mar. Res., 40(Suppl.), 329-339.

Lukas, R., S. P. Hayes and K. Wrytki, 1984: Equatorial sea level response during the 1982-1983 E. Nino. J. Geophys. Res., 89, $10425-10430$.

Luther, D. S., 1980: Observations of long period waves in the tropical oceans and atmosphere. Ph.D. dissertation, Massachusetts Institute of Technology-Woods Oceanographic Institution Joint Program in Oceanography, $210 \mathrm{pp}$.

Philander, S. G. H., and A. D. Seigel, 1985: Simulation of El Niño of 1982-1983, Coupled Ocean-Atmosphere Models. Proc. of the 16th Liege Collog. on Ocean Hydrodynamics: Hydrodynamics of the Equatorial Ocean, J. C. J. Nihoul, Ed., Elsevier, N. Y. 517-541.

- D. Halpern, D. Hansen, R. Legeckis, L. Miller, C. Paul, R. Watts, R. Weisberg and M. Wimbush, 1985: Long waves in the equatorial Pacific Ocean. Eos, Trans. Amer. Geophys. Union, 66, p. 154.

Ripa, P., and S. P. Hayes, 1981: Evidence for equatorial trapped waves at the Galapagos. J. Geophys. Res., 86, 6509-6516.

Stevenson, J. W., and P. P. Niiler, 1983: Upper ocean heat budget during the Hawaii-to-Tahiti Shuttle Experiment. J. Phys. Oceanogr., 13, 1894-1907.

Wallace, J. M., and R. E. Dickinson, 1972: Empirical orthogonal representation of time series in the frequency domain. I. Theoretical considerations. J. Appl. Meteor., 11, 887-900.

Weisberg, R. H., and C. Colin, 1986: Equatorial Atlantic Ocean temperature and current variations during 1983 and 1984. Nature, $322,240-243$.

-, J. H. Hickman, T. Y. Tang and T. J. Weingartner, 1987a: Velocity and temperature observations during the Seasonal Response of the Equatorial Atlantic Experiment at $0^{\circ}, 28^{\circ} \mathrm{W} . J$. Geophys. Res., 92, 5061-5075.

- D. Halpern, T. Y. Tang and S. M. Hwang, 1987b: $\mathrm{M}_{2}$ tidal currents in the eastern equatorial Pacific Ocean. J. Geophys. Res., 92, 3821-3826. 